\title{
Analyzing the Physical and Mental Quality of College Students Using Multidimensional Data Mining
}

\author{
Yuanhong Mu \\ School of Economics and Trade, Guangdong Mechanical and Electrical Polytechnic, Guangzhou 510515, China \\ Correspondence should be addressed to Yuanhong Mu; 2014020014@gdmec.edu.cn
}

Received 30 September 2021; Revised 27 October 2021; Accepted 30 October 2021; Published 17 November 2021

Academic Editor: Fazlullah Khan

Copyright (c) 2021 Yuanhong Mu. This is an open access article distributed under the Creative Commons Attribution License, which permits unrestricted use, distribution, and reproduction in any medium, provided the original work is properly cited.

\begin{abstract}
Shaping the healthy psychology of college students and promoting the healthy growth of talents are the goals that colleges and universities should strive for in moral education. The mobile Internet era has brought opportunities and challenges to the psychological quality education of college students. In order to effectively cope with the existing challenges, it is imperative to explore a psychological quality education model that conforms to the new environment. Therefore, this article has carried out the analysis and management of the physical and mental quality of college students based on multidimensional data mining. By adopting exploratory factor analysis and confirmatory factor analysis methods, this paper establishes a structural equation model of students' psychological quality. Through the theoretical discussion of psychological quality, the connotation and characteristics of the psychological quality of college students are further defined. We should discuss the relationship between psychological quality and other psychological phenomena and provide suggestions for college students' psychological quality. There is a need for an empirical research program for the quality structure and actual psychological quality structure. Finally, we conducted a multidimensional evaluation of the program through the TOPSIS evaluation model and confirmed the effectiveness of the program.
\end{abstract}

\section{Introduction}

The task of modern colleges and universities is no longer to train students who study with great concentration in the ivory tower, but to train a large number of innovations that can bravely face the challenges of the knowledge economy, adapt to the high-tech, high-efficiency, and high-competitive requirements of modern society, and have good comprehensive qualities $[1,2]$. On the other hand, the mental health of college students has always been a phenomenon that society has paid more and more attention to. This shows that due to the long-term disconnection from society, talents with higher academic qualifications are more ideal in their spiritual world, and they have psychological endurance and communication skills. Defects, especially in the process of collective life, are prone to some friction and contradictions, which have an impact on mental health [3]. Therefore, the status of psychological quality education is becoming more and more significant. In the process of psychological quality education, the component that can maximize the effect of education is the psychological quality education model $[4,5]$. The psychological quality education model should also be adjusted and innovated according to the new situation.

Russell F. Waugh selected 8 elements and 100 indicators that affect the comprehensive quality of students and comprehensively evaluated 3000 Australian college students using the Rasch model of item response theory, and based on the analysis results [6], Centra John A adopts the adjacent index comparison method to study the influence of comprehensive quality. It is a procedure to determine the importance of each index in the evaluation by comparing the selected indexes in pairs [7]. Maintaining mental health means maintaining and improving the individual's adaptation to the environment, reducing problematic behaviors, and the principles and measures for the prevention and treatment of mental illness [8]. The definition of college students' mental health can be summarized as the individual being able to adapt to the current and developing 
environment, having perfect personality characteristics, cognition, emotional response, and volitional action in a positive state, and maintaining normal regulatory abilities [9].

Therefore, psychological quality education is particularly important in the process of moral education. Based on this theoretical premise, this article attempts to start with the positive and negative effects of the new media environment on the psychological quality. On the basis of summarizing and summarizing the traditional psychological quality education model, it explores the new educational environment [10-12]. In order to effectively cope with the existing challenges, it is imperative to explore a psychological quality education model that conforms to the new environment. Therefore, this article has carried out the analysis and management of the physical and mental quality of college students based on multidimensional data mining. Through the analysis and differentiation of the existing psychological quality structure model, and the discussion of the relationship between psychological quality and other psychological phenomena, an empirical research program of the expected psychological quality structure and actual psychological quality structure of college students is proposed.

\section{Psychological Quality Structure}

Some scholars have made a certain discussion on the structure of psychological diathesis. In summary, we can find that they have some commonalities. Psychological quality is composed of a variety of psychological components, including cognitive components and noncognitive components, including psychological ability components, as well as mental health and social adaptation components $[13,14]$. There are both emotional and dynamic components as well as conscious components. Psychological quality is a self-organizing system composed of various functional elements. Psychological quality is composed of various levels of psychological components, including both the trait level and the behavioral habit level [15]. There are both quality levels and potential levels. Some scholars believe that high-quality individuals in modern society should possess self-disciplined moral sentiments, adaptive cognition and behavioral abilities, and motivation to pursue excellence. They also have a balanced value system, an integrated self-regulation system, an open-minded outlook on life, and other philosophical psychological elements [16, 17]. Undoubtedly, these construction commonalities are of great reference value for this research. A schematic diagram of the existing mental quality structure is presented in Figure 1.

As a model, the model of psychological quality education has its essential characteristics. First of all, the psychological quality education model is derived from reality; it is an abstraction and generalization of reality, that is, the psychological quality education model is derived from the practice of realistic psychological quality education activities and is a theorized generalization and summary of actual practical activities [18-20]. Secondly, the psychological quality education model is a theoretical expression, which cannot be compared with the simple psychological quality education method; otherwise, it will reduce the theoretical level and value of the psychological quality education model. Finally, the model is a high-level generalization of the theory. In the practical activities of psychological quality education, relevant theoretical results can be extracted.

\section{Multifactor Analysis of Students' Physical and Mental Quality}

3.1. Cluster Analysis of Physical and Mental Quality Indicators. K-means algorithm is a clustering algorithm, which is a representative of a typical prototype-based objective function clustering method. There are both emotional and dynamic components as well as conscious components. Psychological quality is a self-organizing system composed of various functional elements. Psychological quality is composed of various levels of psychological components, including both the trait level and the behavioral habit level. It uses a certain distance from the data point to the prototype as the optimized objective function and iterates by using the method of seeking the extreme value of the function [21-23].

The input is the sample set, the category $N=\left\{x_{1}, x_{2}, \ldots, x_{m}\right\}$ of each physical and mental quality, the cluster tree $k$ of the cluster, the maximum number of iterations $R$, and the output is the cluster partition $M=\left\{M_{1}, M_{2}, \ldots, M_{k}\right\}$. Among them, the cluster is divided into $\left(M_{1}, M_{2}, \ldots, M_{k}\right)$, and the center points of $K$ clusters are randomly selected as $u_{1}, u_{2}, \ldots, u_{i}$, then the goal is to minimize the square error $S$.

$$
S=\sum_{i=1}^{k} \sum_{x \in M_{i}}\left\|x-u_{i}\right\|_{2}^{2},
$$

where $u_{i}$ is the mean vector of cluster $M_{i}$, also called centroid, and the expression is

$$
u_{i}=\frac{1}{\left|M_{i}\right|} \sum_{x \in M_{i}} x .
$$

Randomly select $k$ centroid vectors $\left\{u_{1}, u_{2}, \ldots, u_{k}\right\}$ from the dataset $N$ A:

For $r=1,2, \ldots, R$, initialize the cluster partition $M$ B to $M_{t}=\varnothing, t=1,2, \ldots, k$.

For $i=1,2, \ldots, m$, calculate each $u_{j}(j=1,2, \ldots, k)$ centroid vector:

$$
d_{i j}=\left\|x_{i}-u_{j}\right\|_{2}^{2}
$$

Mark the smallest $x_{i}$ as the category $\eta_{i}$ corresponding to $d_{i j}$, and update it to

$$
\begin{gathered}
M_{\eta_{i}}=M_{\eta_{i}} \cup\left\{x_{i}\right\}, \\
u_{j}=\frac{1}{\left|M_{j}\right|} \sum_{x \in M_{j}} x .
\end{gathered}
$$




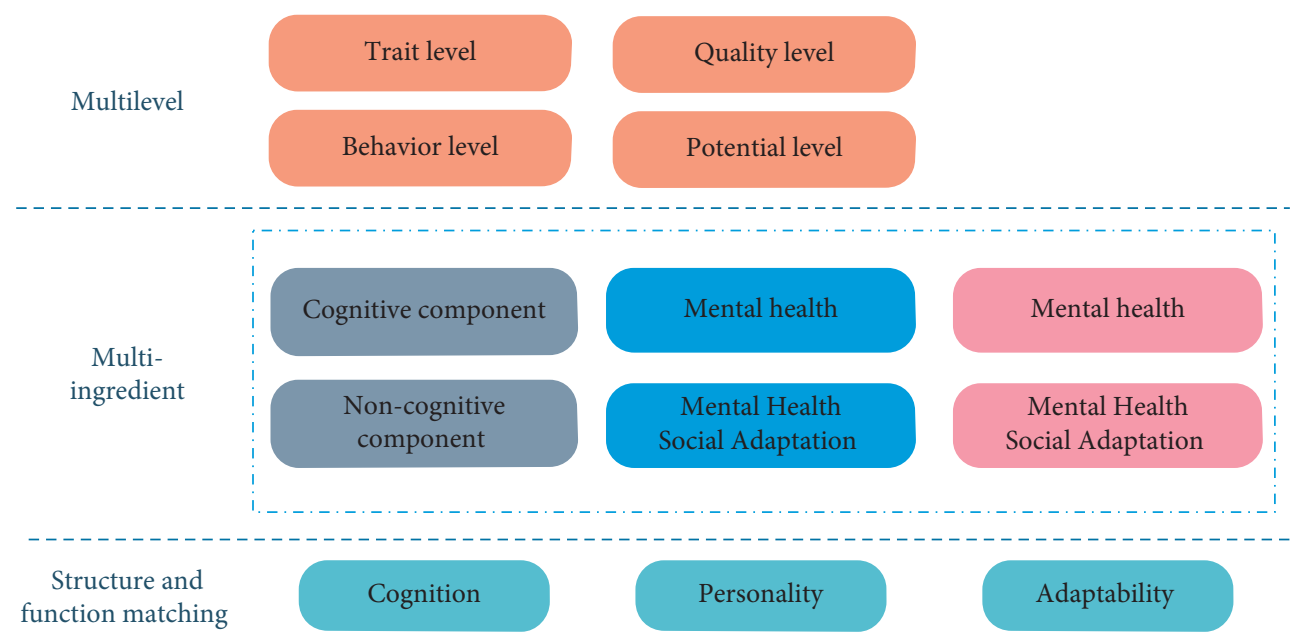

FIGURE 1: Schematic diagram of the existing mental quality structure.

If all $k$ centroid vector has not changed, go to the previous step.

Output cluster partition $M=\left\{M_{1}, M_{2}, \ldots, M_{K}\right\}$.

3.2. Eigenvalues and Eigenvectors. The maximum eigenvalue of matrix $\mathrm{A}$ is $\lambda_{\max }$, and the corresponding eigenvector is

$$
u=\left(u_{1}+u_{2}+u_{3}+\cdots+u_{n}\right)^{T} .
$$

Normalize $u$, that is, to $i=1,2, \ldots, n$, that is,

$$
X_{i}=\frac{u_{i}}{\sum_{i=1}^{n} u_{j}} \text {. }
$$

The consistency check index is

$$
\mathrm{CI}=\frac{\lambda_{\max }-n}{n-1} \text {. }
$$

( $n$ is the order of the matrix, where $n=7$ ), the consistency ratio $\mathrm{CR}=\mathrm{CI} / \mathrm{RI}$. When $\mathrm{CI} / \mathrm{RI}<0.1$, the matrix is said to have consistency. The consistency index is the result described in Table 1.

Bringing A into the test index to obtain 0.1211, 0.0961, the value is less than 0.1 , so it can be said that the matrix $A$ is consistent.

\section{Validation of Student's Physical and Mental Quality Model}

4.1. TOPSIS Evaluation Model. In order to verify that the multidimensional data mining proposed in this paper can analyze and manage, we conducted a multidimensional evaluation of the program through the TOPSIS evaluation model and confirmed the effectiveness of the program $[24,25]$. The definition of college students' mental health can be summarized as the individual being able to adapt to the current and developing environment, having perfect personality characteristics, cognition, emotional response, and volitional action in a positive state and maintaining normal regulatory abilities.

The theoretical process of TOPSIS evaluation model is as follows:
TABle 1: Consistency index RI table.

\begin{tabular}{lcccccccc}
\hline Matrix order & 2 & 3 & 4 & 5 & 6 & 7 & 8 & 0 \\
\hline RI & 0 & 0.56 & 0.92 & 1.13 & 1.29 & 1.27 & 1.43 & 1.54 \\
\hline
\end{tabular}

Suppose the task is represented by $A=\left\{a_{1}, a_{2}, a_{3}, \ldots, a_{n}\right\}$, there are $m$ indicators for evaluating the possibility of completion of the task, which is recorded as indicator set $F=\left\{f_{1}, f_{2}, f_{3}, \ldots, f_{m}\right\}$. Construct the original data matrix, and carry out qualitative and quantitative calculations through the third determined analysis and evaluation index of college students' physical and mental quality, and obtain the initial matrix as

$$
Z=\left\{\begin{array}{cccc}
z_{11} & z_{12} & \cdots & z_{1 m} \\
z_{21} & z_{22} & \cdots & z_{2 m} \\
\vdots & \vdots & \vdots & \vdots \\
z_{n 1} & z_{n 2} & \cdots & z_{n m}
\end{array}\right\}=\left\{z_{i j}\right\}_{n \times m}
$$

where $z_{i j}$ represents the value $(1 \leq i \leq n, 1 \leq j \leq m)$ of the $j^{\text {th }}$ influencing factor of the $i^{\text {th }}$ task. Standardize the matrix. Since there are two different forms of indicators in the evaluation system, positive indicators and inverse indicators, different types of indicators are standardized so that the processed indicators have the nature of positive indicators.

For positive indicators,

$$
x_{i j}=\frac{z_{i j}-z_{i}^{\min }}{z_{i}^{\max }-z_{i}^{\min }}, i=1,2, \ldots, n .
$$

In the formula, $z_{i}^{\min }$ and $z_{i}^{\max }$ are the index $F_{j}$, respectively.

For inverse indicators,

$$
x_{i j}=\frac{z_{i}^{\max }-z_{i j}}{z_{i}^{\max }-z_{i}^{\min }}, i=1,2, \ldots, n .
$$

After standardization, the original value of each indicator ranges from 0 to 1 . Thus, the standardized matrix $X=$ $\left(x_{i j}\right)$ is obtained. 


$$
V^{-}=\min _{i} z_{i j}, i=1,2, \ldots, m
$$

It is a set of positive ideal solutions, while negative ideal solutions are the opposite. Calculate the distance between each sample.

$$
\begin{aligned}
& D_{i}^{+}=\sqrt{\sum_{j=1}^{m}\left|v_{i j}-v_{j}^{+}\right|^{2}}, i=1,2, \ldots, m, \\
& D_{i}^{-}=\sqrt{\sum_{j=1}^{m}\left|v_{i j}-v_{j}\right|^{2}}, i=1,2, \ldots, m .
\end{aligned}
$$

Calculate the closeness of each sample to the positive ideal solution, and confirm the closeness of the sample to the credit rating.

$$
C_{i}=\frac{D_{i}^{-}}{\left(D_{i}^{-}+D_{i}^{+}\right)} .
$$

Among them, the closer to 1 , the closer the sample is to the positive ideal solution, that is, the higher the credit rating. Standardize the matrix. Since there are two different forms of indicators in the evaluation system, positive indicators and inverse indicators, different types of indicators are standardized so that the processed indicators have the nature of positive indicators.

The closer to 0 , the lower the credit rating and the worse the credit. Now, set 0.5 as the benchmark.

$$
h_{(y)}=\left\{\begin{array}{l}
0.3 \leq y \leq 0.5 \\
0.1 \leq y \leq 0.3 \\
0 \leq y \leq 0.1 \\
-0.3 \leq y \leq 0 \\
-0.5 \leq y \leq-0.3
\end{array} .\right.
$$

Taking the data of factors affecting the physical and mental quality of college students as the original data, substituting it into the model to solve, sorting out the implementation effect of the new project pricing plan is shown in Table 2.

By observing the results of the model, it can be known that the pricing scheme has achieved a good implementation effect and improved the quality of task completion. In order to further analyze and evaluate the results, we selected three indicators of behavior habits, trait levels, and potential levels to evaluate the performance of the model. The quality scores of college students under the three indicators are shown in Figure 2. Figure 3 shows the difference results of students' physical and mental quality under different indicators.

The definition of college students' mental health can be summarized as the individual being able to adapt to the current and developing environment, having perfect personality characteristics, cognition, emotional response, and volitional action in a positive state and maintaining normal regulatory abilities. In order to verify that the multidimensional data mining proposed in this paper can analyze and manage, we conducted a multidimensional evaluation of the program
TABLE 2: The implementation effect of data on factors affecting the physical and mental quality of college students.

\begin{tabular}{lccc}
\hline Sample category code & $C_{i}$ & $y$ & $h_{(y)}$ (implementation effect) \\
\hline 1 & 0.85 & 0.35 & Good \\
2 & 0.81 & 0.31 & Good \\
3 & 0.86 & 0.36 & Good \\
4 & 0.79 & 0.29 & Better \\
5 & 0.87 & 0.37 & Good \\
6 & 0.84 & 0.34 & Good \\
7 & 0.86 & 0.36 & Good \\
8 & 0.83 & 0.33 & Good \\
\hline
\end{tabular}

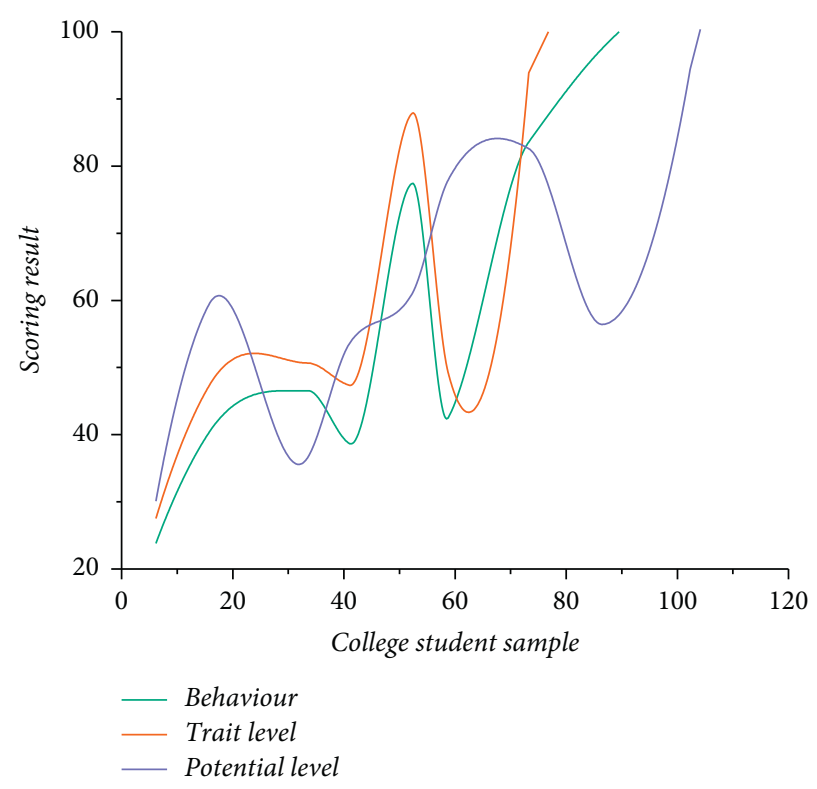

FIGURE 2: Scores of students' physical and mental quality under different indicators.

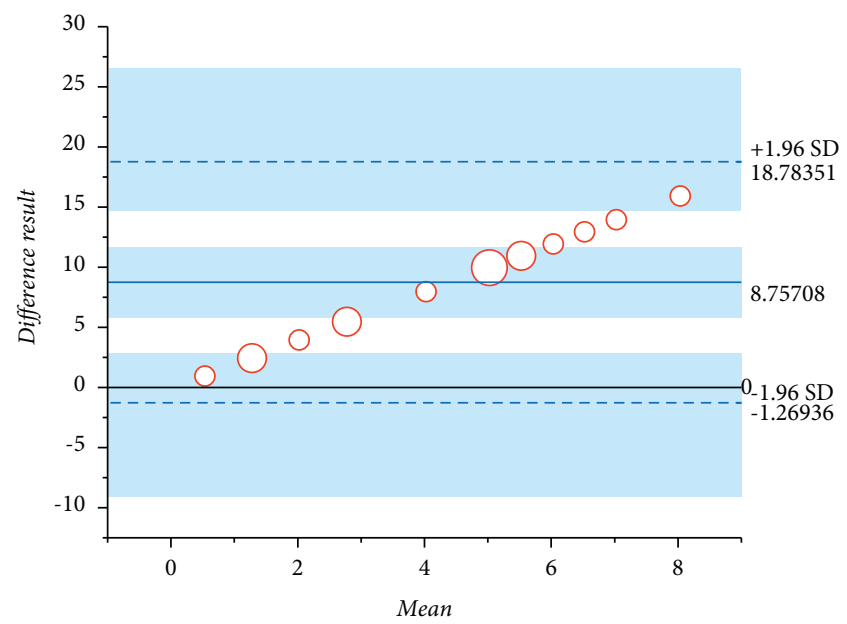

FIGURE 3: Difference results of students' physical and mental quality under different indicators.

through the TOPSIS evaluation model and confirmed the effectiveness of the program. The K-means clustering algorithm is very sensitive to outliers and may also cause errors. As a 
model, the model of psychological quality education has its essential characteristics. First of all, the psychological quality education model is derived from reality; it is an abstraction and generalization of reality, that is, the psychological quality education model is derived from the practice of realistic psychological quality education activities and is a theorized generalization and summary of actual practical activities.

\subsection{Suggestions for Physical and Mental Quality Management.} At present, there are still problems in the evaluation of the comprehensive quality of college students. These problems should be further solved to improve the effectiveness of the evaluation of the comprehensive quality of college students. Idea is the guide of action and the guide of practice. Whether the evaluation concept is scientific or not, it directly affects the evaluation practice $[26,27]$. Therefore, to effectively carry out the comprehensive quality evaluation of college students, it is necessary to establish a scientific evaluation concept. The purpose of assessment is not only to identify the pros and cons and to classify students, but its more important purpose is to point to the development and improvement of students. The current assessment has a relatively single purpose. Scientific evaluation content is the requirement of quality education and is the basis for giving full play to the effectiveness of evaluation. To further improve evaluation, we must start with the evaluation content [28, 29]. The current assessments pay more attention to the three aspects of students' "moral education, intellectual education, and physical education," and the content of the assessment also revolves around them, while ignoring the needs of the society and employers for students. The selection of evaluation methods is related to whether the evaluation results are fair and objective, and whether the evaluation can achieve the expected goals [30]. Therefore, in order to improve the traditional and single problems of current evaluation methods, multiple evaluation methods must be adopted. Colleges and universities are the makers and executors of evaluation methods, regulations, and rules, and whether their preparation, implementation, and feedback are in place is directly related to the effectiveness of evaluation. First of all, make preparations for the evaluation. The evaluation plan is formulated by the organization personnel of the university and is implemented by the evaluation team and the student leaders. There is a deviation in the understanding of the evaluation regulations by the evaluation personnel and students due to different perspectives. Therefore, at the beginning of the implementation of evaluation, it is necessary for colleges and universities to organize school administrators, teachers, student administrators, and even student leaders to study evaluation methods and regulations.

\section{Conclusion}

Compared with any previous period, the $21^{\text {st }}$ century has higher and more comprehensive requirements for the quality of talents, and contemporary college students also need more psychological guidance. Shaping the healthy psychology of college students and promoting the healthy growth of talents are the goals that colleges and universities should strive for in moral education. In order to effectively cope with the existing challenges, it is imperative to explore a psychological quality education model that conforms to the new environment. Therefore, this article has carried out the analysis and management of the physical and mental quality of college students based on multidimensional data mining. By adopting exploratory factor analysis and confirmatory factor analysis methods, this paper establishes a structural equation model of students' psychological quality. This article expounds the relevant theories of the comprehensive quality evaluation of college students, points out the problems in the comprehensive quality evaluation of college students, analyzes the influencing factors, and puts forward corresponding countermeasures. Although many scholars have done a lot of research, the problem of college students' mental health is a complicated and long-term problem. This article also strives to explain the methods and approaches of mental health education from both theoretical and practical aspects. However, due to time, funding, and conditions, this study only selected some students as the survey objects.

5.1. Future Work. Future research can expand the sample size and selection range in order to have a more comprehensive understanding of the true state of contemporary college students' mental health. Future research focuses on the implementation effects of the plan, the improvement and perfection of research and the plan, and the establishment of the next evaluation system.

\section{Data Availability}

The data of the study are generally included in the body of the article.

\section{Conflicts of Interest}

The author declares no conflicts of interest.

\section{Acknowledgments}

This work was supported by Guangdong Province Educational Science “Thirteenth Five-Year Plan" Party Building Research Project "An Analysis of the Deep Integration Mechanism of Party Building Work and Education and Teaching in Colleges and Universities in the New Era Based on the Perspective of Curriculum Ideological and Political" (2019JKDJ029) and Guangdong Quality Engineering Educational Reform Project "A Comprehensive Study of the Management Mode of Internship Practice for Mechanical and Electrical Professionals under the Background of the Information Age Based on the Perspective of Diagnosis and Improvement” (GDJG2019061).

\section{References}

[1] A. A. De Graaff, M. T. D’Hooghe, G. A. T. Dunselman et al., "The significant effect of endometriosis on physical, mental and social wellbeing: results from an international crosssectional survey," Human Reproduction, vol. 28, no. 10, 2013. 
[2] A. Puig-Ribera, I. Martínez-Lemos, M. Giné-Garriga et al., "Self-reported sitting time and physical activity: interactive associations with mental well-being and productivity in office employees," BMC Public Health, vol. 15, 2015.

[3] K. E. Weaver, L. P. Forsythe, B. B. Reeve et al., "Mental and physical health-related quality of life among us cancer survivors: population estimates from the 2010 national health interview survey," Cancer Epidemiology, Biomarkers \& Prevention, vol. 21 , no. 11, 2012.

[4] G. D. Mishra, R. Hockey, and A. J. Dobson, "A comparison of Sf-36 summary measures of physical and mental health for women across the life course," Quality of Life Research, vol. 23, no. $5,2014$.

[5] N. Schlesinger, D. Radvanski, and P. Tomanovich, "Sat0353association of gouty arthritis severity with patients' mental and physical health-related quality of life, work productivity and medical resource utilization," Annals of the Rheumatic Diseases, vol. 72, no. Suppl 3, p. A703, 2013.

[6] S. T. Amann, D. YaDaV, M. M. BarmaDa et al., "Physical and mental quality of life in chronic pancreatitis," Pancreas, vol. 42, no. 2, pp. 293-300, 2013.

[7] C. Bennett, A. Underdown, and J. Barlow, "Massage for promoting mental and physical health in typically developing infants under the age of six months," Cochrane Database of Systematic Reviews (Online), vol. 4, no. 4, p. CD005038, 2013.

[8] V. Lindhom, J. Lahti, O. Rahkonen, E. Lahelma, and T. Lallukka, "Joint association of physical activity and body weight with subsequent physical and mental functioning: a follow-up study," BMC Public Health, vol. 13, no. 1, p. 197, 2013.

[9] M. A. Andrykowski, "Physical and mental health status and health behaviors in male breast cancer survivors: a national, population-based, case-control study," Psycho-Oncology, vol. 21, no. 9, pp. 927-934, 2012.

[10] A. L. Rebar, M. J. Duncan, C. Short, and C. Vandelanotte, "Differences in health-related quality of life between three clusters of physical activity, sitting time, depression, anxiety, and stress," BMC Public Health, vol. 14, no. 1, pp. 1088-1096, 2014.

[11] B. Manrique-Espinoza, A. Salinas, J. Avila-Funes, and L. Gutierrez-Robledo, "Sarcopenia is associated with physical and mental components of quality of life in older adults," Innovation in Aging, vol. 1, no. suppl_1, p. 774, 2017.

[12] K. Tamai, A. Suzuki, H. Terai et al., "Time-course of physical and mental well-being improvements after cervical surgery," Spine, vol. 46, no. 5, 2020.

[13] J. Vignato, Y. Perkhounkova, S. Saeidzadeh, M. Patsais, and L. S. Segre, "Pathways from pain to physical and mental health-related quality of life during the third trimester of pregnancy: an exploratory mediation analysis," Journal of Clinical Nursing, vol. 30, no. 9-10, 2021.

[14] S. Bhattacharya and D. Ghosh, "Studying physical and mental health status among Hijra, Kothi and transgender community in Kolkata, India-sciencedirect," Social Science \& Medicine, vol. $265,2020$.

[15] L. Daimiel, M. A. Martínez-González, D. Corella et al., "Physical fitness and physical activity association with cognitive function and quality of life: baseline cross-sectional analysis of the predimed-plus trial," Scientific Reports, vol. 10, no. 1, p. 3472, 2020.

[16] M. Yu, J. Jin, X. Wang, X. Yu, D. Zhan, and J. Gao, "Development and design of flexible sensors used in pressuremonitoring sports pants for human knee joints," IEEE Sensors Journal, vol. 17, no. 4, pp. 201-222, 2021.
[17] J. S. Oliveira, C. Sherrington, E. Zheng, M. R. Franco, and A. Tiedemann, "Effect of interventions using physical activity trackers on physical activity in people aged 60 years and over: a systematic review and meta-analysis," British Journal of Sports Medicine, vol. 54, no. 20, p. 100324, 2019.

[18] J. Hu, J. Fang, Y. Du, Z. Liu, and P. Ji, "Application of pls algorithm in discriminant analysis in multidimensional data mining," The Journal of Supercomputing, vol. 75, no. 9, pp. 6004-6020, 2019.

[19] C. Proietti, M. Zakrzewski, T. S. Watkins et al., "Mining, visualizing and comparing multidimensional biomolecular data using the genomics data miner (gmine) web-server," Scientific Reports, vol. 6, no. 1, p. 38178, 2016.

[20] T. Su, Y. Shi, J. Yu, C. Yue, and F. Zhou, "Nonlinear compensation algorithm for multidimensional temporal data: a missing value imputation for the power grid applications," Knowledge-Based Systems, vol. 215, p. 106743, 2021.

[21] B. Kovalerchuk and V. Grishin, "Adjustable general line coordinates for visual knowledge discovery in n-d data," Information Visualization, vol. 18, no. 1, pp. 3-32, 2019.

[22] W. Wei, B. Gao, L. Tie-Yan, T. Wang, G. Li, and H. Li, "A ranking approach on large-scale graph with multidimensional heterogeneous information," IEEE Transactions on Cybernetics, vol. 46, no. 4, 2016.

[23] J. Xu, Y. Chen, J. Zhao, Q. Hang, and X. Li, "Water environment random evaluation model based on the improved topsis method and bayesian theory and its application," Water Resources, vol. 46, no. 3, pp. 344-352, 2019.

[24] X. Wang and Q. Duan, "Improved ahp-topsis model for the comprehensive risk evaluation of oil and gas pipelines," $\mathrm{Pe}$ troleum Science, vol. 16, 2019.

[25] Y. Wang, J. R. Chardonnet, and F. Merienne, "Enhanced cognitive workload evaluation in $3 \mathrm{~d}$ immersive environments with topsis model," International Journal of Human-Computer Studies, vol. 147, p. 102572, 2021.

[26] Z. Wu, Q. Li, D. Kong, G. Chen, and D. Luo, “The anp-fuzzytopsis model for the optimization of the scheme of largesection blasting," Arabian Journal of Geosciences, vol. 13, no. 2, 2020.

[27] M. Yu, T. Quan, Q. Peng, X. Yu, and L. Liu, “A model-based collaborate filtering algorithm based on stacked autoEncoder," Neural Computing \& Applications, vol. 9, no. 3, pp. 98-112, 2021.

[28] L. Boqiang, Y. Muhammad, and Raza, "Performance evaluation of medical device manufacturers using a hybrid fuzzy mcdm," Journal of Cleaner Production, vol. 11, no. 6, pp. 524-533, 2019.

[29] J. Li, Y. Sun, L. Gong, N. Chai, and Y. Yin, "Multiattribute fuzzy decision evaluation approach and its application in enterprise competitiveness evaluation," Mathematical Problems in Engineering, vol. 2021, no. 1, 11 pages, 2021.

[30] A. Rdvan, A. Fuat, and K. G. Dilek, "A single valued neutrosophic multicriteria group decision approach with dpl mil opsis method based on optimization," International Journal of Intelligent Systems, vol. 19, no. 3, pp. 1123-1135, 2021. 